\title{
9,9-Diarylfluorene-Based Poly(alkyl aryl ether)s: Synthesis and Property
}

\author{
By Hideki HAYASHI, ${ }^{1}$ Masayo TAKIZAWA, ${ }^{2}$ Takayuki ARAI,${ }^{2}$ Keisuke IKEDA, ${ }^{1}$ Wataru TAKARADA, ${ }^{1}$ \\ Takeshi KIKUTANI, ${ }^{1}$ Yasuhito KOYAMA,${ }^{1}$ and Toshikazu TAKATA ${ }^{1, *}$
}

Polyethers possessing 9,9-diarylfluorene moieties in the main chain (F-PEs 3) were synthesized in $85-99 \%$ yields by the polycondensation of 9,9-bis(hydroxyaryl)fluorenes with alkyl ditosylates in the presence of cesium carbonate. Molecular weight of the F-PEs was dependent on the structure of the ditosylate 1; cyclohexyl-1,4-dimethylene (1a), 1,2-ethylene (1b), 1,3-trimethylene (1c), and 1,6-hexamethylene (1d). Higher molecular weight F-PEs $\left(M_{\mathrm{n}} 32000-60000, M_{\mathrm{w}}\right.$ 74000-160000) was obtained when longer alkyl chain ditosylates (1a and 1d) were used. The F-PEs showed good solubility toward various organic solvents such as toluene and high $5 \%$ weight loss temperature $\left(T_{\mathrm{d} 5}: 424-447^{\circ} \mathrm{C}\right)$. The glass transition temperature of F-PEs $\left(T_{\mathrm{g}}\right)$ was ranging from 147 to $220^{\circ} \mathrm{C}$. No melting point $\left(T_{\mathrm{m}}\right)$ was observed. F-PEs showed high water-resistance. The transmittance of F-PEs in film state (thickness: $21-32 \mu \mathrm{m}$ ) reached over $90 \%$ in the visible region. The F-PEs exhibited high refractive indices in a range of $1.62-1.66$ at $590 \mathrm{~nm}$ in addition to sufficiently low birefringence values, probably due to the cardo structure of the fluorene moiety placed in the main chain. The structural dependence of dispersing ability to fullerene $\mathrm{C}_{60}$ was investigated.

KEY WORDS: Cardo Structure / Polyether / Refractive Index / Birefringence / Solubility / Thermal Stability / Processability /

9,9-Diarylfluorene-based polymers attract much attention due to the unique characteristics originated from the "cardo" structure as characterized often by the high refractive index and low birefringence. ${ }^{1-9}$ Such optical property is caused by the presence of many aromatic rings in the 9,9-diarylfluorene moiety which occupy the different planes to disturb the interchromophore packing, effectively decreasing the optical anisotropy. Meanwhile, such polymers also display excellent filler-dispersing ability ${ }^{10-12}$ in addition to their high thermal stability, ${ }^{13-16}$ high solubility, ${ }^{17-19}$ and so on. ${ }^{20-25}$ We have recently reported the special $\pi-\pi$ interaction of the 9,9diarylfluorene moiety in the matrix polymers toward $\pi$-face of the carbon fillers. ${ }^{26}$ Although many polymers possessing 9,9-diarylfluorene moieties in the main chain have been developed to date, ${ }^{1-30}$ there is no study on polyethers. Polyethers are an important class of high performance engineering thermoplastics with a favorable combination of physical, mechanical, and chemical properties, other than processability, ${ }^{31-41}$ and are easily synthesized usually by the polycondensation of diols and ditopic electrophiles. Polyethers with good optical and physical properties can be obtained, ${ }^{42,43}$ if saturated alkyl group is introduced into the polymer main chain in addition to 9,9-diarylfluorene moiety, because the alkyl group often shows no optical anisotropy.

Herein, we wish to disclose the synthesis and property of poly(alkyl aryl ether)s (F-PEs) containing 9,9-diarylfluorene moiety in the main chain, with emphasis on the effect of alkyl chain on the polymer property such as thermal property, waterresistance, and optical property.

\section{EXPERIMENTAL}

\section{Materials and Methods}

9,9-Bis(4-hydroxyphenyl)fluorene (2a) and 9,9-bis(4-hydroxy-3-methylphenyl)fluorene (2b) (provided by Osaka Gas Co., Ltd.) were used after drying in vacuo at $100^{\circ} \mathrm{C}$ for $5 \mathrm{~h}$. All solvents used in this work were dried over freshly activated molecular sieves 4A. Other commercially available materials were used without further purification.

${ }^{1} \mathrm{H}$ NMR $(400 \mathrm{MHz})$ spectra were recorded on a JEOL AL400 spectrometer using $\mathrm{CDCl}_{3}$ as the solvent and tetramethylsilane as the internal standard. Molecular weight and its distribution were measured by a gel permeation chromatography (GPC) on a JASCO Gulliver system equipped with two consecutive liner polystyrene gel columns (TOSOH TSKgel G2000HXL and GMHXL) at $30^{\circ} \mathrm{C}$, eluted with $\mathrm{CHCl}_{3}$ at a flow rate of $0.85 \mathrm{~mL} / \mathrm{min}$, and calibrated using polystyrene standards. IR spectra were recorded on a JASCO FT/IR-230 spectrometer. Thermogravimetry (TG) was performed on a Shimadzu TGA-50 instrument at a heating rate of $10^{\circ} \mathrm{C} / \mathrm{min}$ under $\mathrm{N}_{2}$ atmosphere (flow rate of $50 \mathrm{~mL} / \mathrm{min}$ ) to determine decomposition temperature $T_{\mathrm{d} 5}$ at which $5 \%$ weight loss was observed. Differential scanning calorimetry (DSC) was carried out using a Shimadzu DSC-60 instrument at a heating rate of $5{ }^{\circ} \mathrm{C} / \mathrm{min}$ under $\mathrm{N}_{2}$ atmosphere (flow rate of $50 \mathrm{~mL} / \mathrm{min}$ ) to determine glass transition temperature $T_{\mathrm{g}}$. Transmittance and filler dispersing ability of polymer films were evaluated by a UV-visible spectrophotometer (UV-550, JASCO) with the scanning range from $220 \mathrm{~nm}$ to $800 \mathrm{~nm}$. The X-ray diffraction

\footnotetext{
${ }^{1}$ Department of Organic and Polymeric Materials, Tokyo Institute of Technology, 2-12-1, Ookayama, Meguro, Tokyo 152-8552, Japan

${ }^{2}$ Material Engineering Group, Enplas Laboratories, Inc., 2-38-5, Namiki, Kawaguchi 332-0034, Japan

*To whom correspondence should be addressed (Tel: +81-3-5734-2898, Fax: +81-3-5734-2888, E-mail: takata.t.ab @m.titech.ac.jp).
} 
(XRD) profiles of the F-PE films were measured by a X-ray diffractometer (Miniflex/CW/S, Rigaku Co.), which was performed by the reflect method among $2 \theta$ range of 5-60 with an interval 0.02. Refractive index of polymers was measured with a spectroscopic ellipsometer (Mass-102, Five Lab.). Birefringence of the films was evaluated by taking the picture of the film placed between two cross axes polarizing films. Retardations were measured by an automatic birefringence analyzer (KOBRA-CCD, Oji Scientific Instruments) under the parallel-Nicols $(590 \mathrm{~nm})$.

Typical Experimental Procedure for the Synthesis of Ditosylate (1d). To a mixture of 1,6-hexanediol (50.1 g, $0.424 \mathrm{~mol}$ ) and pyridine $(107 \mathrm{~mL}, 1.32 \mathrm{~mol})$ in $\mathrm{CH}_{2} \mathrm{Cl}_{2}(180 \mathrm{~mL})$ was added portionwise $p$-toluenesulfonyl chloride $(177 \mathrm{~g}, 0.928$ mol) at $-15^{\circ} \mathrm{C}$. The mixture was warmed to $0{ }^{\circ} \mathrm{C}$ and stirred for $24 \mathrm{~h}$. The mixture was diluted with $\mathrm{CH}_{2} \mathrm{Cl}_{2}$ and washed with $10 \%$ aq. $\mathrm{HCl}$ and $10 \%$ aq. $\mathrm{NaCl}$. The organic layer was dried over $\mathrm{MgSO}_{4}$, filtrated, and concentrated in vacuo. The solid material formed was recrystallized from $\mathrm{MeOH}$ to give 1,6-hexamethylene ditosylate (1d, $167 \mathrm{~g}, 93 \%)$ as white solids; m.p. $69.5-71.5^{\circ} \mathrm{C}$ (lit. $\left.70.0-71.5^{\circ} \mathrm{C}\right) .44$

Typical Experimental Procedure for the Polycondensation of 9,9-Bis(4-hydroxyphenyl)fluorene (2a) and 1,6-Hexamethylene Ditosylate (1d). To a mixture of 9,9-bis(4-hydroxyphenyl)fluorene (2a, $3.50 \mathrm{~g}, 10.0 \mathrm{mmol})$, 1,6-hexamethylene ditosylate (1d, $4.26 \mathrm{~g}, 10.0 \mathrm{mmol})$ in mesitylene-DMSO $(10 \mathrm{~mL}, 7: 3$ $(\mathrm{v} / \mathrm{v}))$ was added $\mathrm{Cs}_{2} \mathrm{CO}_{3}(10.6 \mathrm{~g}, 32.5 \mathrm{mmol})$ at room temperature. The mixture was warmed to $150{ }^{\circ} \mathrm{C}$ and stirred for $3 \mathrm{~h}$ under an argon atmosphere. The resulting mixture was cooled to room temperature and diluted with toluene $(100 \mathrm{~mL})$ to precipitate inorganic materials, which were filtered off. The filtrate was washed with water, and then poured into $\mathrm{MeOH}$. The precipitates formed were collected by filtration, and the solid product was dried in vacuo at room temperature for $1 \mathrm{~d}$. To the product dissolved in $\mathrm{CHCl}_{3}(200 \mathrm{~mL})$ was added activated charcoal $(6.0 \mathrm{~g})$. The mixture was stirred at room temperature overnight and filtrated. The filtrate was poured into $\mathrm{MeOH}$ to give F-PE 3d $(3.66 \mathrm{~g}, 85 \%)$ as a white solid; $M_{\mathrm{n}}$ $60000, M_{\mathrm{w}} 160000, M W D 2.7 ; T_{\mathrm{g}} 147^{\circ} \mathrm{C}, T_{\mathrm{d} 5} 444{ }^{\circ} \mathrm{C} ;{ }^{1} \mathrm{H}$ NMR $\left(400 \mathrm{MHz}, \mathrm{CDCl}_{3}, 298 \mathrm{~K}\right) \delta 7.72(\mathrm{~d}, 2 \mathrm{H}, J=7.4 \mathrm{~Hz}), 7.35(\mathrm{~d}$, $2 \mathrm{H}, J=7.4 \mathrm{~Hz}), 7.31(\mathrm{t}, 2 \mathrm{H}, J=7.4 \mathrm{~Hz}), 7.22(\mathrm{t}, 2 \mathrm{H}, J=$ $7.4 \mathrm{~Hz}), 7.08(\mathrm{~d}, 4 \mathrm{H}, J=8.6 \mathrm{~Hz}), 6.70(\mathrm{~d}, 4 \mathrm{H}, J=8.6 \mathrm{~Hz})$, 3.85 (t, 4H, $J=6.4 \mathrm{~Hz}), 1.72(\mathrm{br}, 4 \mathrm{H}), 1.45$ (br, 4H) ppm; IR (neat) 3035, 2938, 2863, 1607, 1507, 1472, 1447, 1245, 1178, 1013, 823, $747 \mathrm{~cm}^{-1}$; Elemental Analysis Calcd: C, 86.06\%; H, $6.52 \%$; Found: C, $85.84 \%$; H, 6.23\%.

F-PE 3a. White solid (91\%, cis:trans $=18: 82) ; M_{\mathrm{n}} 32000$, $M_{\mathrm{w}} 74000, M W D 2.3 ; T_{\mathrm{g}} 220^{\circ} \mathrm{C}, T_{\mathrm{d} 5} 441^{\circ} \mathrm{C} ;{ }^{1} \mathrm{H}$ NMR $(400$ $\left.\mathrm{MHz}, \mathrm{CDCl}_{3}, 298 \mathrm{~K}\right) \delta 7.73(\mathrm{~d}, 2 \mathrm{H}, J=7.4 \mathrm{~Hz}), 7.36(\mathrm{~d}, 2 \mathrm{H}$, $J=7.4 \mathrm{~Hz}), 7.32(\mathrm{t}, 2 \mathrm{H}, J=7.4 \mathrm{~Hz}), 7.23(\mathrm{t}, 2 \mathrm{H}, J=7.4 \mathrm{~Hz})$, $7.08(\mathrm{~d}, 4 \mathrm{H}, J=8.6 \mathrm{~Hz}), 6.70(\mathrm{~d}, 4 \mathrm{H}, J=8.6 \mathrm{~Hz}), 3.76(\mathrm{~d}$, $0.7 \mathrm{H}, J=6.3 \mathrm{~Hz}), 3.67(\mathrm{~d}, 3.3 \mathrm{H}, J=6.3 \mathrm{~Hz}), 2.0-1.8(\mathrm{~m}$, $3.7 \mathrm{H}), 1.71$ (br, 1.7H), 1.6-1.4 (m, 1.3H), 1.1-0.9 (m, 3.3H) ppm; IR (neat) 3035, 2918, 2854, 1606, 1507, 1466, 1447, 1244, 1177, 1031, 822, $746 \mathrm{~cm}^{-1}$; Elemental Analysis Calcd: C, $86.43 \%$; H, 6.59\%; Found: C, 86.47\%; H, 6.40\%.
F-PE 3b. White solid (94\%); $M_{\mathrm{n}}$ 6100, $M_{\mathrm{w}}$ 13000, $M W D 2.1$; $T_{\mathrm{g}} 200^{\circ} \mathrm{C}, T_{\mathrm{d} 5} 439{ }^{\circ} \mathrm{C} ;{ }^{1} \mathrm{H}$ NMR $\left(400 \mathrm{MHz}, \mathrm{CDCl}_{3}, 298 \mathrm{~K}\right) \delta$ $7.71(\mathrm{~d}, 2 \mathrm{H}, J=7.4 \mathrm{~Hz}), 7.4-7.3(\mathrm{~m}, 4 \mathrm{H}), 7.22(\mathrm{t}, 2 \mathrm{H}, J=$ $7.4 \mathrm{~Hz}), 7.07(\mathrm{~d}, 4 \mathrm{H}, J=8.6 \mathrm{~Hz}), 6.72(\mathrm{~d}, 4 \mathrm{H}, J=8.6 \mathrm{~Hz})$, 4.2-4.1 (m, 4H) ppm; IR (neat) 3035, 2927, 2875, 1606, 1506, 1447, 1241, 1178, 1069, 939, 823, $745 \mathrm{~cm}^{-1}$; Elemental Analysis Calcd: C, $86.14 \%$; H, 5.36\%; Found: C, $85.96 \%$; H, $5.33 \%$.

F-PE 3c. White solid (97\%); $M_{\mathrm{n}} 6800, M_{\mathrm{w}}$ 19000, $M W D 2.9$; $T_{\mathrm{g}} 185^{\circ} \mathrm{C}, T_{\mathrm{d} 5} 447^{\circ} \mathrm{C} ;{ }^{1} \mathrm{H}$ NMR $\left(400 \mathrm{MHz}, \mathrm{CDCl}_{3}, 298 \mathrm{~K}\right) \delta$ $7.71(\mathrm{~d}, 2 \mathrm{H}, J=7.4 \mathrm{~Hz}), 7.4-7.3(\mathrm{~m}, 4 \mathrm{H}), 7.21(\mathrm{t}, 2 \mathrm{H}, J=$ $7.4 \mathrm{~Hz}), 7.06(\mathrm{~d}, 4 \mathrm{H}, J=8.8 \mathrm{~Hz}), 6.69(\mathrm{~d}, 4 \mathrm{H}, J=8.8 \mathrm{~Hz})$, $4.00(\mathrm{t}, 4 \mathrm{H}, J=5.6 \mathrm{~Hz}$ ), 2.12 (quintet, $2 \mathrm{H}, J=5.6 \mathrm{~Hz}$ ) ppm; IR (neat) 3035, 2933, 2876, 1606, 1507, 1471, 1447, 1243, 1178, 1060, 823, $745 \mathrm{~cm}^{-1}$; Elemental Analysis Calcd: C, $86.13 \%$; H, 5.68\%; Found: C, $86.04 \%$; H, 5.61\%.

F-PE 3e. White solid (99\%); $M_{\mathrm{n}} 32000, M_{\mathrm{w}} 110000, M W D$ 3.3; $T_{\mathrm{g}} 208{ }^{\circ} \mathrm{C}, T_{\mathrm{d} 5} 424{ }^{\circ} \mathrm{C} ;{ }^{1} \mathrm{H}$ NMR $\left(400 \mathrm{MHz}, \mathrm{CDCl}_{3}, 298 \mathrm{~K}\right)$ $\delta 7.72(\mathrm{~d}, 2 \mathrm{H}, J=7.4 \mathrm{~Hz}), 7.37(\mathrm{~d}, 2 \mathrm{H}, J=7.4 \mathrm{~Hz}), 7.31(\mathrm{t}$, $2 \mathrm{H}, J=7.4 \mathrm{~Hz}), 7.23(\mathrm{t}, 2 \mathrm{H}, J=7.4 \mathrm{~Hz}), 7.0-6.9(\mathrm{~m}, 4 \mathrm{H})$, $6.59(\mathrm{~d}, 2 \mathrm{H}, J=8.5 \mathrm{~Hz}), 3.77(\mathrm{~d}, 0.7 \mathrm{H}, J=6.8 \mathrm{~Hz}), 3.69(\mathrm{~d}$, $3.3 \mathrm{H}, J=5.7 \mathrm{~Hz}), 2.09(\mathrm{~s}, 6 \mathrm{H}), 1.8-2.0(\mathrm{~m}, 3.7 \mathrm{H}), 1.75(\mathrm{br}$, $1.7 \mathrm{H}), 1.7-1.5(\mathrm{~m}, 1.3 \mathrm{H}), 1.2-1.0(\mathrm{~m}, 3.3 \mathrm{H}) \mathrm{ppm}$; IR (neat) 3019, 2919, 2854, 1605, 1500, 1465, 1447, 1249, 1131, 1031, 806, $742 \mathrm{~cm}^{-1}$; Elemental Analysis Calcd: C, 86.38\%; H, 7.04\%; Found: C, $86.10 \%$; H, 6.97\%.

\section{Film Preparation}

Polymer films of the F-PEs for the evaluation of refractive index and retardation were prepared by a heat-press method (200-260 ${ }^{\circ} \mathrm{C}$ ) using the corresponding polymers which were dried in vacuo at $80^{\circ} \mathrm{C}$. The films for the evaluation of transmittance and XRD profiles were prepared by casting from the toluene solutions of the corresponding polymers at room temperature.

\section{RESULTS AND DISCUSSION}

\section{Synthesis and Structure of F-PEs}

We first examined the polycondensation of 9,9-bis(4hydroxyphenyl)fluorene (2a, BPF) as the cardo monomers and ditosylate 1a (cis:trans $=18: 82$ ) for the preparation of F-PEs (Scheme 1). The polycondensation of $\mathbf{2 a}$ with $\mathbf{1 a}$ in the presence of $\mathrm{Cs}_{2} \mathrm{CO}_{3}$ was conducted in a few solvents capable of solubilizing 1a, 2a, and $\mathbf{3 a}$ in some extents. The results are summarized in Table I. It turned out that the mixed solvent of mesitylene:DMSO (7:3 (v/v)) was a suitable solvent which gave the corresponding polyether 3a with $M_{\mathrm{n}} 32000$ and $M_{\mathrm{w}}$ 74000 (entry 3). The polycondensation in DMSO alone resulted in the lowering of the molecular weight probably due to the low solubility of $\mathbf{3 a}$ (entry 1), while that in mesitylene was also unfruitful owing to the low solubility of $\mathrm{Cs}_{2} \mathrm{CO}_{3}$ (entry 6). In addition, the prolonged reaction time caused the coloration of the resulting polymer due mostly to the oxidation of the phenol moieties (entry 4). The polycondensations of $\mathbf{2}$ with a few ditosylates $\mathbf{1}$ were examined in the mixed 

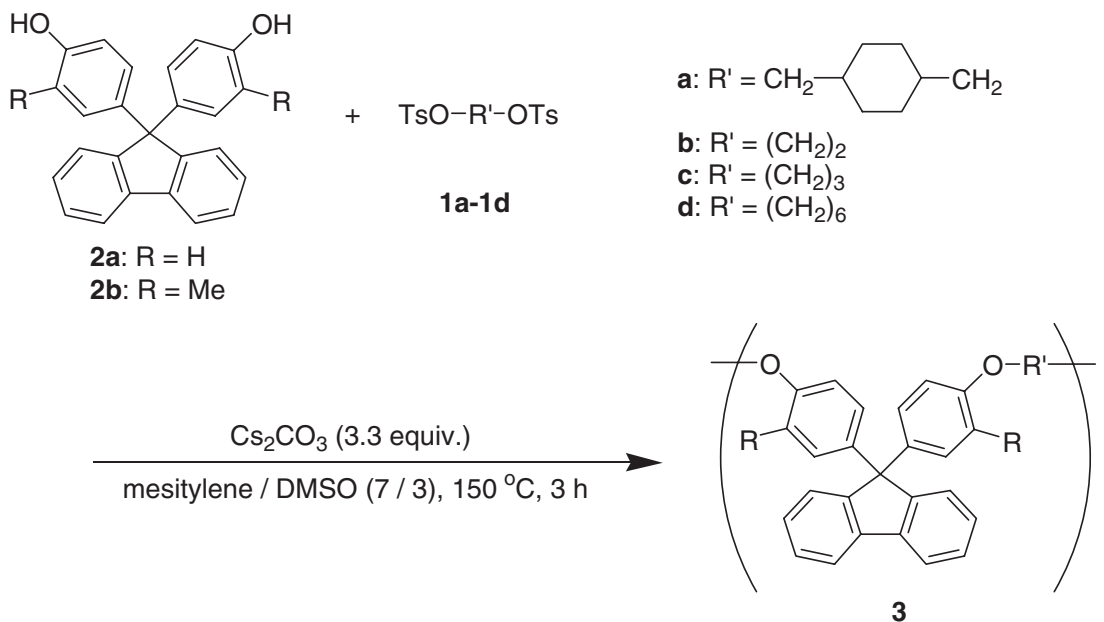

Scheme 1.

Table I. Effect of solvent on the synthesis of F-PE $3 a^{a}$

\begin{tabular}{|c|c|c|c|c|c|c|}
\hline Entry & Mesitylene/DMSO Ratio & Time/h & Yield $^{\mathrm{b}} / \%$ & $M_{\mathrm{n}}{ }^{\mathrm{C}}$ & $M_{\mathrm{w}}{ }^{\mathrm{c}}$ & $M W D^{c}$ \\
\hline 1 & 0:10 (DMSO only) & 3 & 85 & 4500 & 28000 & 6.3 \\
\hline 2 & $5: 5$ & 3 & 77 & 22000 & 73000 & 3.4 \\
\hline 3 & $7: 3$ & 3 & 91 & 32000 & 74000 & 2.3 \\
\hline 4 & $7: 3$ & 6 & 90 & 26000 & 62000 & 2.4 \\
\hline 5 & $9: 1$ & 3 & 87 & 31000 & 80000 & 2.6 \\
\hline 6 & 10:0 (Mesitylene only) & 3 & 77 & 6100 & 13000 & 2.1 \\
\hline
\end{tabular}

${ }^{a} \mathrm{~A}$ mixture of $\mathbf{2 a}(10.0 \mathrm{mmol})$ and $1 \mathbf{a}(10.0 \mathrm{mmol})$ was heated in the presence of $\mathrm{Cs}_{2} \mathrm{CO}_{3}(32.5 \mathrm{mmol})$ in a solvent $(10 \mathrm{~mL})$ at $150{ }^{\circ} \mathrm{C}$ under an argon atmosphere. bYield of $\mathrm{MeOH}$-insoluble part. ${ }^{\mathrm{c}}$ Estimated by $\mathrm{GPC}$ using polystyrene standards $\left(\mathrm{eluent:} \mathrm{CHCl}_{3}\right)$.

Table II. Synthesis of F-PEs 3 from 2 and $\mathbf{1}^{\mathrm{a}}$

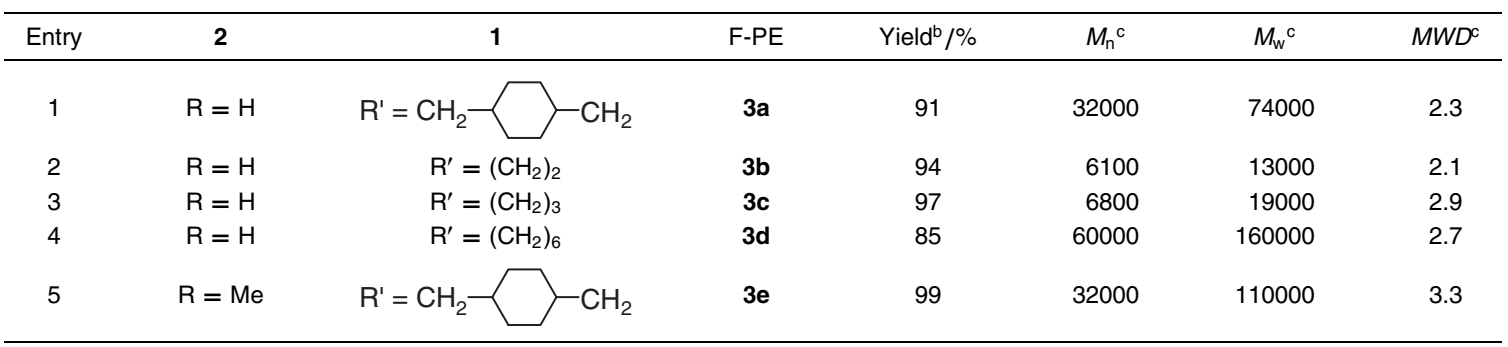

${ }^{a} \mathrm{~A}$ mixture of $2(10.0 \mathrm{mmol})$ and $1(10.0 \mathrm{mmol})$ was heated in the presence of $\mathrm{Cs}_{2} \mathrm{CO}_{3}(32.5 \mathrm{mmol})$ in a mixed solvent $(10 \mathrm{~mL}$; mesitylene/DMSO; $7 / 3(\mathrm{v} / \mathrm{v}))$ at $150^{\circ} \mathrm{C}$ for $3 \mathrm{~h}$ under an argon atmosphere. ${ }^{\text {b }}$ Yield of $\mathrm{MeOH}$-insoluble part. ${ }^{\mathrm{C}}$ Estimated by GPC using polystyrene standards (eluent: $\mathrm{CHCl}_{3}$ ).

solvent system (Table II). The molecular weight of $\mathbf{3 a}\left(M_{\mathrm{n}}\right.$ $\left.32000, M_{\mathrm{w}} 74000\right), 3 d\left(M_{\mathrm{n}} 60000, M_{\mathrm{w}} 160000\right)$, and $3 \mathbf{e}\left(M_{\mathrm{n}}\right.$ $\left.32000, M_{\mathrm{w}} 110000\right)$ were higher than those of $\mathbf{3 b}\left(M_{\mathrm{n}} 6100\right.$, $\left.M_{\mathrm{w}} 13000\right)$ and 3c $\left(M_{\mathrm{n}} 6800, M_{\mathrm{w}} 19000\right)$. This is probably owing to the low reactivity originated from the steric hindrance on the nucleophilic displacement between the monomers, as suggested by the MM2 calculation. There seems no effect of the methyl substituents at the ortho position of the phenolic nucleophile.

Figure 1 shows ${ }^{1} \mathrm{H}$ NMR spectra of F-PEs 3. All aromatic signals of $\mathbf{3}$ appeared sharply in any case, which suggested high degree of polymerization and low degree of disorderliness in polymer structure as recognized from the polymerization type. In the spectrum of $\mathbf{3 a}$, the signals based on the structural isomerism around the cyclohexyl group appeared separately $(\mathbf{g}$ : methylene of $\mathrm{ArOCH}_{2-}$ (cis), h: methylene of $\mathrm{ArOCH}_{2-}$ (trans), i: $\mathrm{CH}$ (cis), j: Cy-eq-H (trans), k: CH (trans), l: Cyeq-H (cis), m: Cy-ax-H (cis), n: Cy-ax-H (trans)). The cis:trans ratio in $\mathbf{3 a}$ reflected the cis:trans ratio of $\mathbf{1 a}$, suggesting that the reactivity of the two diastereomers 1a was almost same in the polymerization. The same thing was observed in F-PE 3e. IR spectral data also supported the polyether structure; a strong broad absorption at $1300-1200 \mathrm{~cm}^{-1}$ and a medium broad absorption at $1100-1000 \mathrm{~cm}^{-1}$ for alkyl aryl ether linkage..$^{53}$

\section{Solubility}

Solubility of $\mathbf{3}$ toward organic solvents was evaluated and the results are shown in Table III. All polymers were highly 

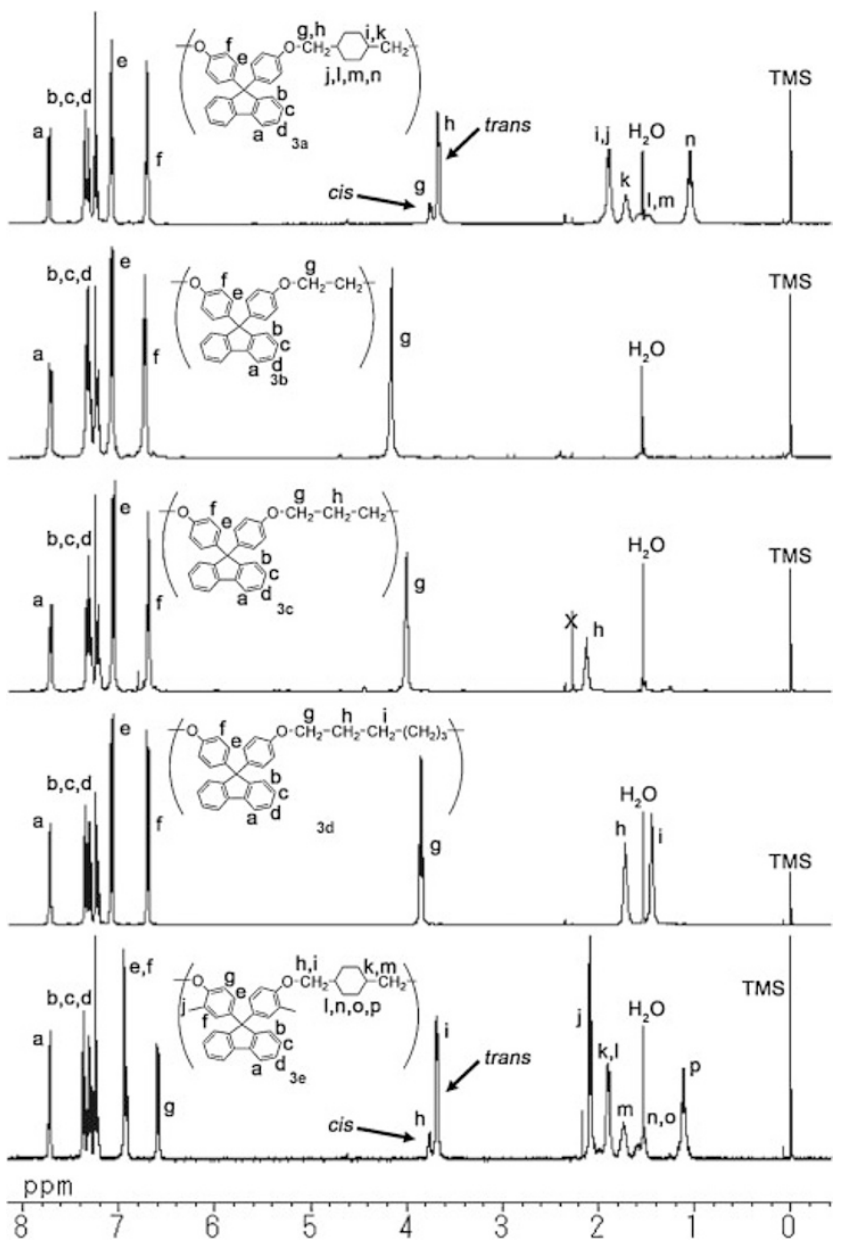

Figure 1. ${ }^{1} \mathrm{H} \mathrm{NMR}$ spectra $\left(400 \mathrm{MHz}, \mathrm{CDCl}_{3}, 298 \mathrm{~K}\right)$ of F-PEs 3.

Table III. Solubility behavior of F-PEs 3 to organic solvents

\begin{tabular}{cccccccc}
\hline F-PE & $\mathrm{CHCl}_{3}$ & THF & toluene & acetone & $\mathrm{MeCN}$ & $\mathrm{MeOH}$ & hexane \\
\hline 3a & + & + & + & - & - & - & - \\
$3 \mathbf{b}$ & + & + & + & - & - & - & - \\
$3 \mathbf{c}$ & + & + & + & - & - & - & - \\
$3 \mathbf{d}$ & + & + & + & - & - & - & - \\
$3 \mathbf{e}$ & + & + & + & - & - & - & - \\
\hline
\end{tabular}

${ }^{\text {a }}$-PE $(100 \mathrm{mg})$ was added in a solvent $(1 \mathrm{~mL})$ and stirred at room temperature: + , soluble; - , insoluble.

soluble in typical organic solvents such as toluene, $\mathrm{CHCl}_{3}$, and THF. The high solubility of $\mathbf{3}$ presumably comes from the 9,9diarylfluorene moieties as the "cardo" in the main chain, like other polymers. ${ }^{17-19}$

\section{Thermal Property}

Thermal property of $\mathbf{3}$ was evaluated by TGA and DSC under nitrogen atmosphere (Figures 2 and 3 ). The 5\% weight loss temperature $\left(T_{\mathrm{d} 5}\right)$ of $\mathbf{3}$ was high enough; $441^{\circ} \mathrm{C}$ (3a), $439^{\circ} \mathrm{C}(\mathbf{3 b}), 447^{\circ} \mathrm{C}(3 \mathbf{c}), 444^{\circ} \mathrm{C}(3 \mathbf{d})$, and $424^{\circ} \mathrm{C}$ (3e). There was no clear difference in $T_{\mathrm{d} 5}$ of $\mathbf{3}$ with different alkyl chains. No melting point $\left(T_{\mathrm{m}}\right)$ was observed in any case, being clearly consistent with the amorphous nature of the F-PEs. $T_{\mathrm{g}}$ of the F-
PEs undoubtedly depended on the structure of the alkyl chain: $220{ }^{\circ} \mathrm{C}(3 \mathbf{a}), 200^{\circ} \mathrm{C}(3 \mathbf{b}), 185^{\circ} \mathrm{C}(\mathbf{3 c}), 147^{\circ} \mathrm{C}(3 \mathbf{d})$, and $208^{\circ} \mathrm{C}$ (3e). This result suggests the easy control of $T_{\mathrm{g}}$ of the F-PE.

\section{Water-Resistance}

Water-resistance of the F-PEs 3a and 3d was evaluated using the films. The films were prepared by casting from the toluene solution of them. The film of a polyester possessing 9,9-diarylfluorene moiety with main chain $^{5}$ was used for comparison. These films were heated in water at $80^{\circ} \mathrm{C}$ for $8 \mathrm{~h}$. The results were shown in Figure 4. The clear polyester film remarkably became clouded along with its deformation. In contrast to it, the films of F-PEs showed no change in its film shape and transparency. These films were subjected to the measurements of the molecular weight and thermal stability. However, no decrease in molecular weight and weight of the films was observed in all polymers. The results seem to suggest that the heating in water caused the crystallization of the polyester. Thus, the F-PEs were proved to have good waterresistant property.

\section{Transparency}

Colorless transparent thin films of the F-PEs were readily prepared by casting from the toluene solution (thickness: $21-$ $32 \mu \mathrm{m})$. The transparency of $\mathbf{3 d}$ film was demonstrated in Figure 5 as an example. The transmittance of the films increased from $c a .320 \mathrm{~nm}$, and reached over $c a$. $90 \%$ at $400 \mathrm{~nm}$ in any polymers. In addition, it gradually increased with increase of wavelength in the visible light region (Figure 6). The X-ray diffraction (XRD) analyses of the F-PE cast-films showed only a broad signal in any case, strongly supporting the amorphous nature corresponding to the high transparency of the F-PEs (Figure 7). The amorphous nature certainly comes from the cardo structure of the 9,9-diarylfluorene moiety, which is consistent with the largely decreased interchromophore interaction in or within the polymer chain.

\section{Refractive Index}

Refractive indices of the F-PEs were measured using their thin films which were obtained by a heat-press method at 200$260^{\circ} \mathrm{C}$. The results are summarized in Table IV. The refractive indices were sufficiently high in all five polymers despite their polymer structures consisting only of $\mathrm{C}, \mathrm{H}$, and $\mathrm{O}$ atoms: 1.62 (3a), $1.66(3 \mathbf{b}), 1.65(3 \mathbf{c}), 1.63(\mathbf{3 d})$, and $1.62(3 \mathbf{e})$ at a typical wavelength of $590 \mathrm{~nm}$. The high refractive index values of the F-PEs are probably attributable to the high content of the aromatic rings of the 9,9-diarylfluorene moieties with main chain. The slightly low refractive index of $\mathbf{3 a}, \mathbf{3 d}$, and $\mathbf{3 e}$ compared to $\mathbf{3 b}$ and $\mathbf{3} \mathbf{c}$ would be caused by the reduction of the polymer density, which might come from the rigid alkyl chain. In addition, ortho-methyl group of $\mathbf{3 e}$ afforded no distinct effect on the refractive index.

\section{Birefringence}

Birefringence of F-PEs 3a and 3d was evaluated by taking the picture of their polymer films placed between two cross 


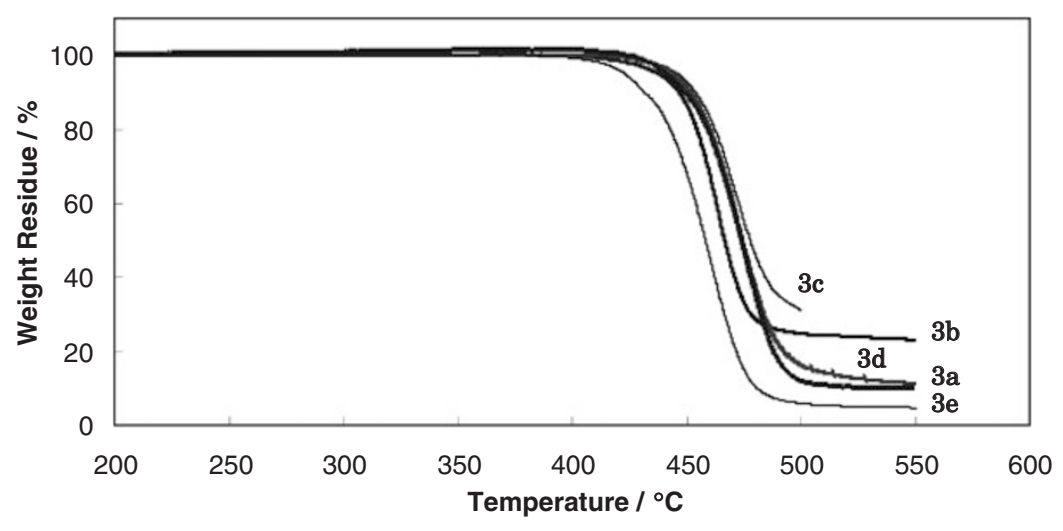

Figure 2. TGA profiles of the F-PEs, measured at a heating rate $10^{\circ} \mathrm{C} / \mathrm{min}$ in $\mathrm{N}_{2}$ atmosphere.

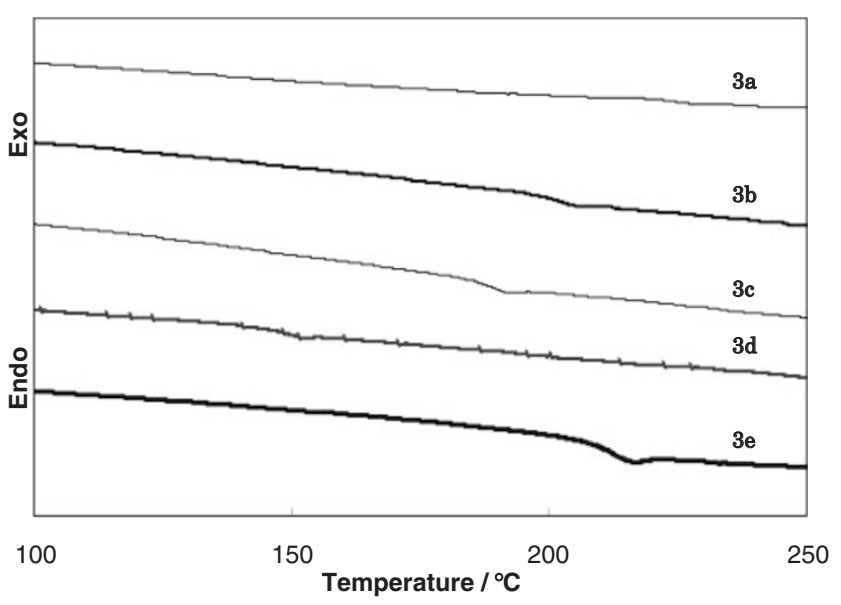

Figure 3. DSC profiles of the F-PEs, measured at a heating rate $5^{\circ} \mathrm{C} / \mathrm{min}$ in $\mathrm{N}_{2}$ atmosphere.

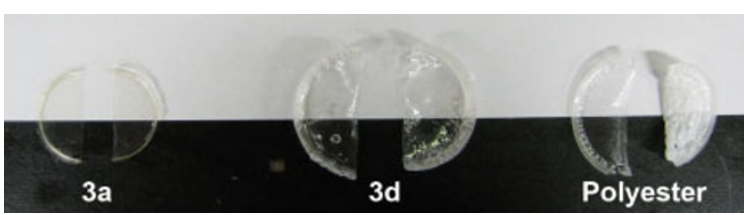

Figure 4. Pictures of the films of $\mathbf{3 a}, \mathbf{3 d}$, and a polyester possessing 9,9diarylfluorene moiety before and after heating at $80^{\circ} \mathrm{C}$ for $8 \mathrm{~h}$ in water (left: before heating, right: after heating).

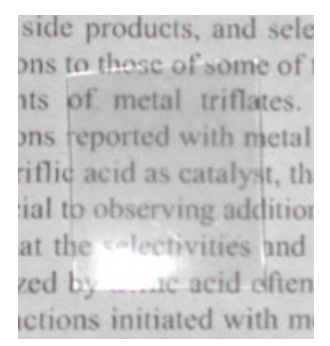

Figure 5. Transparent film of F-PE 3d (film thickness: $520 \mu \mathrm{m}$ ) obtained by casting from the toluene solution at room temperature.

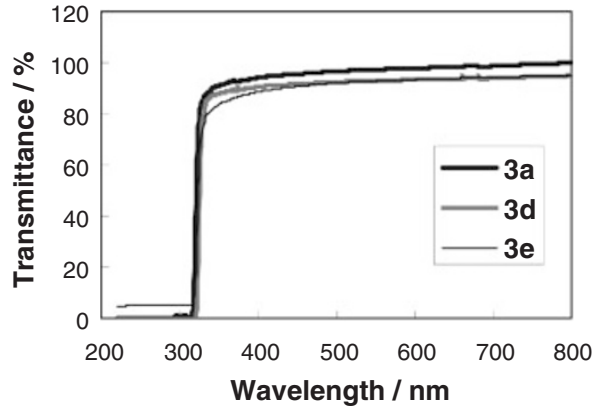

Figure 6. Transmittance of $\mathbf{3}$ in film state measured by a UV-vis spectrometer (film thickness: $21-32 \mu \mathrm{m}$ ).

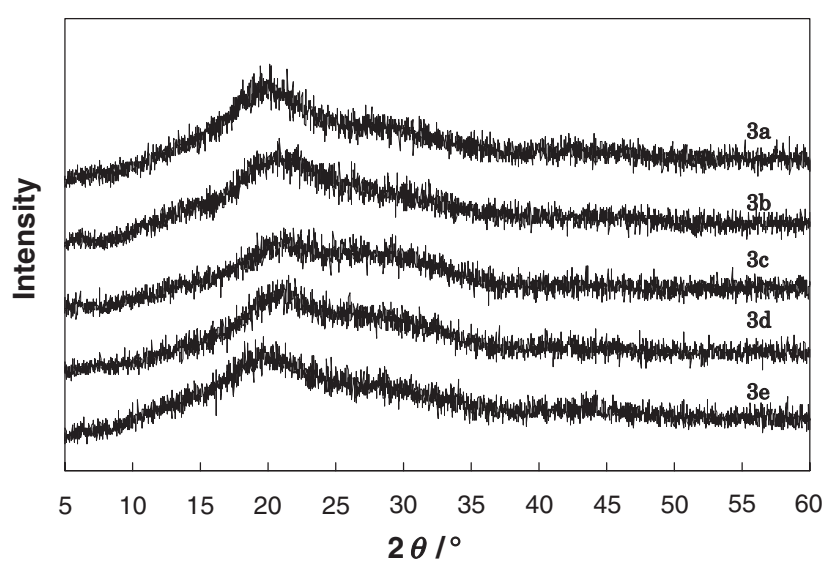

Figure 7. XRD pattern of F-PE films which casted by the toluene solution.

Table IV. Refractive index of F-PEs $3^{\mathrm{a}}$

\begin{tabular}{cccc}
\hline \multirow{2}{*}{ F-PE } & \multicolumn{3}{c}{ Refractive Index } \\
\cline { 2 - 4 } & $485 \mathrm{~nm}$ & $590 \mathrm{~nm}$ & $655 \mathrm{~nm}$ \\
\hline 3a & 1.64 & 1.62 & 1.61 \\
3b & 1.68 & 1.66 & 1.65 \\
3c & 1.67 & 1.65 & 1.64 \\
3d & 1.66 & 1.63 & 1.63 \\
3e & - & 1.62 & - \\
\hline
\end{tabular}

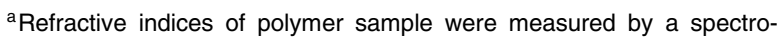
scopic ellipsometer. 


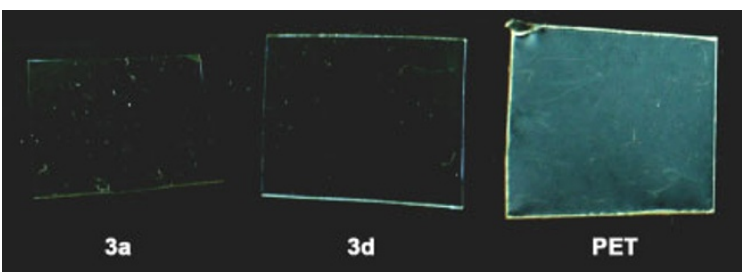

Figure 8. Birefringence of PET and F-PEs 3 under the cross-Nicols.

axes polarizing films (Figure 8). The polymer films were prepared by casting from the toluene solution. Polyethylene terephthalate (PET) film was used for comparison. The PET film had clear birefringence, as showed in Figure 8, while the films of $\mathbf{3 a}$ and $\mathbf{3 d}$ hardly showed the birefringence, in accordance with the reports on other polymers containing 9,9diarylfluorenes. $^{1-9}$ Degree of retardation at $590 \mathrm{~nm}$ in $\mathbf{3 d}$ (thickness: $250 \mu \mathrm{m}$ ) was less than $3.28 \mathrm{~nm}$ in undrawn state, ${ }^{53}$ and the birefringence value was remarkably low (less than $1.3 \times 10^{-5}$ ). In the drawn film of $\mathbf{3 d}$ (drawn ratio is 2.0 ), the birefringence value was $-8.9 \times 10^{-4}$, and the stress optical coefficient was very low $\left(-0.15 \mathrm{GPa}^{-1}\right)$. Such low birefringence should be attributed to the optical anisotropy decreasing effect of the cardo structure of the 9,9-diarylfluorene moiety placed in the main chain as mentioned. ${ }^{1-9}$ The fluorene moiety and the two phenyl groups at the C9-position occupy different planes and are crossed at the precise angle that renders the structure most stable. Placing the aromatic rings on the different planes might disturb their one-directional folding, and thereby the optical anisotropy of the F-PEs disappears.

\section{Dispersing Ability for Fullerene $\mathbf{C}_{60}$}

UV-vis spectrum of fullerene $\mathrm{C}_{60}$ usually shows the characteristic broad absorption at $440-650 \mathrm{~nm}$ originated from the aggregation of $\mathrm{C}_{60} \cdot{ }^{45-52}$ The dispersing ability of the F-PEs was evaluated using $\mathrm{C}_{60}$ as a model filler material. Namely, absorption change of F-PEs $\left(3.00 \times 10^{-3} \mathrm{M} v\right.$ s. unit structure $)$ by the addition of $\mathrm{C}_{60}\left(10 \mathrm{~mL} ; 3.00 \times 10^{-4} \mathrm{M}\right)$ in $\mathrm{CHCl}_{3}$ was observed as decrease of the absorption intensity at 440-650 nm region according to the Armaroli's report. ${ }^{52}$ The spectral change is shown in Figure 9. The absorption intensity at $440 \mathrm{~nm}$ increased in all F-PEs, probably by the increasing interaction between the F-PEs and fullerene $\mathrm{C}_{60}$. The absorption intensity at $440 \mathrm{~nm}$ decreased in the following order of $\mathbf{3 c}$, 3a, and 3d which was in a good agreement with the order of alkyl chain length, i.e., the length between oxygen-oxygen atoms in the main chain. The length was calculated by MM2 as 3c $(4.73 \AA)$, 3a (cis: $7.30 \AA$, trans: $7.57 \AA$ ), and 3d (8.65 $\AA$ ). It seems that the shorter the distance between the neighboring 9,9-diarylfluorene moieties in F-PE is, the more efficient the interaction between F-PE and $\mathrm{C}_{60}$ becomes. Effect of molecular weight on the absorption intensity change was little observed in the case of 3a (Figure 9), being in consistent with the sizes of two molecules F-PE and $\mathrm{C}_{60}$. It is readily concluded that the alkyl chain length affects the dispersing ability of the F-PEs toward $\mathrm{C}_{60}$ as a carbon filler model.

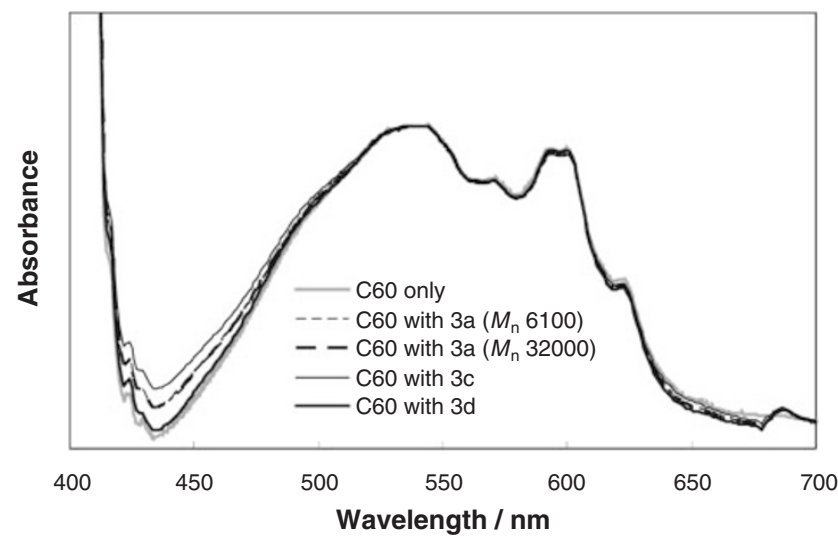

Figure 9. UV-vis absorption spectral change of 3 by the addition of $\mathrm{C}_{60}$ in $\mathrm{CHCl}_{3}$ at $293 \mathrm{~K}$.

\section{SUMMARY}

This paper has disclosed the synthesis and property of poly(alkyl aryl ether)s (F-PEs 3) derived from 9,9-bis(4hydroxyaryl)fluorenes (2) with a few ditosylates (1). The F-PEs showed the relatively high decomposition temperature $T_{\mathrm{d}}$, while the glass transition temperature $T_{\mathrm{g}}$ depended on the structure of the alkyl chain structure in the main chain. Furthermore, the F-PEs had good solubility, which seems to enhance their processability. The F-PEs showed high waterresistance. The transparent films of the F-PEs exhibited high refractive indices in a range of 1.62-1.66, whereas they showed much low birefringence. These characteristic optical properties of the F-PEs come mainly from the cardo structure of the 9,9diarylfluorene skeleton as well as the alkyl chains in the main chain. ${ }^{1-9}$ In addition, the carbon filler $\left(\mathrm{C}_{60}\right)$ dispersing power of the F-PEs was confirmed and decreased with increase in length of the alkyl chain. Thus, the F-PEs can unambiguously be regarded as one of the potential polymer materials being used in a variety of fields including optical materials field.

Electronic Supporting Information Available: Figures S1, $\mathrm{S} 2, \mathrm{~S} 3, \mathrm{~S} 4, \mathrm{~S} 5$ and S6. These materials are available via. the Internet at http://www.spsj.or.jp/c5/pj/pj.htm

Received: February 23, 2009

Accepted: April 15, 2009

Published: June 3, 2009

\section{REFERENCES}

1. A. A. Askadskii, S. N. Prozorova, and G. L. Slonimskii, Vysokomol. Soedin. Ser. A, 18, 636 (1976).

2. T. Kurosaki and T. Teramoto, Jpn. Kokai Tokkyo S63-182336 (1988).

3. S. Suresh, R. J. Gulotty, Jr., S. E. Bales, M. N. Inbasekaran, M. A Chartier, C. Cummins, and D. W. Smith. Jr, Polymer, 44, 5111 (2003).

4. K. Luo, M. Haller, H. Li, H. Tang, K.-Y. A. Jen, K. Jakka, C. Chou, and C. Shu, Macromolecules, 37, 248 (2004). 
5. S. Kawasaki, Denshi Zairyo, 44, 49 (2005).

6. S. Seesukphronrarak, S. Kawasaki, K. Kobori, and T. Takata, J. Polym. Sci., Part A: Polym. Chem., 45, 3073 (2007).

7. S. Kawasaki, M. Yamada, K. Kobori, F. Jin, Y. Kondo, H. Hayashi, Y. Suzuki, and T. Takata, Macromolecules, 40, 5284 (2007).

8. S. Seesukphronrarak and T. Takata, Polym. J., 39, 731 (2007).

9. S. Seesukphronrarak, S. Kawasaki, K. Kobori, and T. Takata, J. Polym. Sci., Part A: Polym. Chem., 46, 2549 (2008).

10. L. Feng, H. Bie, and Z. Chen, J. Appl. Polym. Sci., 98, 434 (2005).

11. L. Feng and Z. Chen, Polymer, 46, 3952 (2005).

12. T. Inada, H. Masunaga, S. Kawasaki, M. Yamada, K. Kobori, and K. Sakurai, Chem. Lett., 34, 524 (2005).

13. Y. Charlier, J. L. Hedrick, T. P. Russell, A. Jonas, and W. Volksen, Polymer, 36, 987 (1995)

14. H. Ghassemi and A. S. Hay, Macromolecules, 26, 5824 (1993).

15. P. W. Morgan, Macromolecules, 3, 536 (1970).

16. K. Tokumitsu, A. Tanaka, K. Kobori, Y. Kozono, M. Yamada, and K. H. Nitta, J. Polym. Sci., Part B: Polym. Phys., 43, 2259 (2005).

17. G. D. Jaycox, Polym. J., 34, 280 (2002).

18. A. K. Salunke, M. Sharma, V. Kute, and S. Banerjee, J. Appl. Polym. Sci., 96, 1292 (2005).

19. C. Yang, Y. Su, and M. Hsu, Polym. J., 38, 132 (2006).

20. K. Yao, M. Koike, Y. Suzuki, K. Sakurai, T. Indo, and K. Igarashi, US Patent 6255031 (2001).

21. H. Okamura, Y. Watanabe, M. Tsunooka, M. Shirai, T. Fujiki, S. Kawasaki, and M. Yamada, J. Photopolym. Sci. Technol., 15, 145 (2002).

22. H. Okamura, K. Sakai, M. Tsunooka, M. Shirai, T. Fujiki, S. Kawasaki, and M. Yamada, J. Photopolym. Sci. Technol., 16, 87 (2003).

23. H. Okamura, C. Harada, M. Tsunooka, T. Fujiki, S. Kawasaki, M. Yamada, and M. Shirai, Kobunshi Ronbunshu, 61, 75 (2004).

24. G. Liou, S. Hsiao, H. Huang, and C. Chang, Polym. J., 39, 448 (2007).

25. H. Okamura, K. Mitsukura, M. Shirai, T. Fujiki, M. Yamada, and S. Kawasaki, J. Photopolym. Sci. Technol., 18, 213 (2005).

26. S. Kawasaki, M. Yamada, K. Kobori, M. Yamada, T. Kakumoto, A. Tarutani, and T. Takata, Polym. J., 39, 115 (2007).

27. J. Seo, K. Cho, and H. Han, Polym. Degrad. Stab., 74, 133 (2001).

28. J.-W. Kang, J. Kim, J. Lee, and J. Kim, J. Lightwave Technol., 23, 364 (2005)

29. C. A. Terraza, J. Liu, Y. Nakamura, Y. Shibasaki, S. Ando, and M. Ueda, J. Polym. Sci., Part A: Polym. Chem., 46, 1510 (2008).

30. N. You, Y. Suzuki, D. Yorifuji, S. Ando, and M. Ueda, Macromolecules, 41, 6361 (2008).
31. M. Nishimura, S. Uemura, H. Yamazaki, M. Kosakai, M. Asano, and A. Yamamoto, Jpn Kokai Tokkyo H10-95640 (1998)

32. P. E. Cassidi, "Thermally Stable Polymers," Marcel Dekker, New York, 1980

33. J. B. Rose, in "High Performance Polymers: Their Origin And Development,” R. B. Seymour and G. S. Kirshenbaum, Ed., Elseiver, New York, 1986.

34. J. L. Hedrick and J. W. Labadie, Macromolecules, 21, 1883 (1988)

35. J. L. Hedrick and J. W. Labadie, Macromolecules, 23, 1561 (1990).

36. J. L. Hedrick, Macromolecules, 24, 812 (1991).

37. S. Banerjee, G. Maier, and M. Burger, Macromolecules, 32, 4279 (1999).

38. Z. Xu, C. Dannenberg, J. Springer, J. S. Benerjee, and G. Maier, Chem. Mater., 14, 3271 (2002).

39. Y. Qi, J. Ding, M. Day, J. Jiang, and C. L. Callender, Chem. Mater., 17, 676 (2005).

40. Y. Chikashige, Y. Chikyu, K. Miyatake, and M. Watanabe, Macromolecules, 38, 7121 (2005).

41. W. Y. Huang, B. R. Liaw, M. Y. Chang, Y. K. Han, and P. T. Huang, Macromolecules, 40, 8649 (2007).

42. Y. Konno, H. Suzuki, H. Kudo, A. Kameyama, and T. Nishikubo, Polym. J., 36, 114 (2004).

43. T. Takajo, A. Takahara, and T. Kichikawa, Polym. J., 40, 716 (2008).

44. A. E. Martin, T. M. Ford, and J. E. Bulkowski, J. Org. Chem., 47, 412 (1982).

45. H. Ajie, M. M. Alvarez, S. J. Anz, R. D. Beck, F. Diederich, K Fostiropoulos, D. R. Huffman, W. Kratschmer, Y. Rubin, K. E. Schriver, D. Sensharma, and L. Whetten, J. Phys. Chem., 94, 8630 (1990).

46. N. Sivaraman, R. Dhamodaran, I. Kaliappan, T. G. Srinivasan, P. R. Vasudeva Reo, and C. K. Mathewsl, J. Org. Chem., 57, 6077 (1992)

47. D. V. Konarev, R. N. Lyubovskaya, N. V. Drichkol, V. N. Semkini, and A. Graja, Synth. Met., 103, 2466 (1999).

48. Y. Marcus, A. L. Smith, M. V. Korobov, A. L. Mirakyan, N. V. Avramenko, and E. B. Stukalin, J. Phys. Chem. B, 105, 2499 (2001).

49. S.-H. Hsiao and H.-W. Chiang, J. Polym. Res., 12, 211 (2005).

50. I. F. Gun'kin and N. Y. Loginova, Russ. J. Gen. Chem., 76, 1911 (2006).

51. I. F. Gun'kin and N. Y. Loginova, Russ. J. Gen. Chem., 76, 1914 (2006).

52. J. Eckert, D. Byrne, J. Nicoud, L. Oswald, J. Nierengarten, M. Numata, A. Ikeda, S. Shinkai, and N. Armaroli, New J. Chem., 24, 749 (2000).

53. Supporting Information. 